\section{Effect of posture and drink volume on the swallowing of capsules}

Drug-induced oesophageal ulceration is an increasingly recognised problem. ${ }^{12}$ Since ulceration is due to a direct irritant effect the passage of the drug must first be delayed. Tablets have been found ${ }^{3}$ to stick in the oesophagus. This study shows the effect of posture and drink volume on the oesophageal transit of capsules.

\section{Patients, methods, and results}

After barium meal and swallow examinations in which normal oesophageal motility was found 50 patients ( 22 men, 28 women, aged 20-87 years) swallowed four standard hard gelatin capsules (Farillon Lok-Cap) filled with $97 \%$ barium sulphate while standing and lying supine with $15 \mathrm{ml}$ and $60 \mathrm{ml}$ water. The time for the capsule to pass from the oropharynx to stomach was measured during screening. If after 10 minutes the capsule remained in the oesophagus, it was washed out with water before proceeding to the next swallow.

Four patterns of capsule movement were seen.

Normal transit-In $28 \%$ of patients all capsules passed into the stomach in $<15$ seconds.

Delayed transit-In $20 \%$ of patients the capsule passed into the stomach in $>20$ seconds without dispersal. Delay occurred at the level of the left main bronchus on one occasion, above the lower oesophageal sphincter on six, and at both sites on eight. All these patients had gastro-oesophageal reflux with or without hiatus hernia. No other consistent relation between radiological diagnosis and pattern of capsule movement was found Five of $22(23 \%)$ patients complained that tablets tended to stick, and three of $14(21 \%)$ normally swallowed tablets without water.

Arrested transit-In 52\% of patients the capsule disintegrated. Capsules lodged at the level of the left main bronchus on seven occasions or above the lower oesophageal sphincter on 29. Disintegration occurred between two and three minutes and the remnants remained adherent for 10 minutes until washed off. This group included eight of $10(80 \%)$ patients with dysphagia for food, five of eight $(62.5 \%)$ who complained of difficulty in swallowing tablets, 14 of $22(64 \%)$ who complained of tablets sticking, and seven of 14 who took tablets without liquid. Most $(68 \%)$ patients said tablets stuck in the throat but this was never shown. Three patients were aware that the capsule had stuck and two localised it correctly.

Delayed by gastro-oesophageal reflux-A capsule was delayed on a column of refluxed barium on 10 occasions and lodged and distintegrated on three. No capsule was seen to reflux from stomach to oesophagus.

The figure shows the clearance of capsules from the oesophagus. Al capsules swallowed while standing with $60 \mathrm{ml}$ water entered the stomach within 5 seconds. The four groups were significantly different at the $p<0.01$ level (Friedman). ${ }^{4}$ Analysed independently the erect position and $60 \mathrm{ml}$ volume had highly significant effects on capsule transit (both $p<0.001$, Wilcoxon) ${ }^{4}$

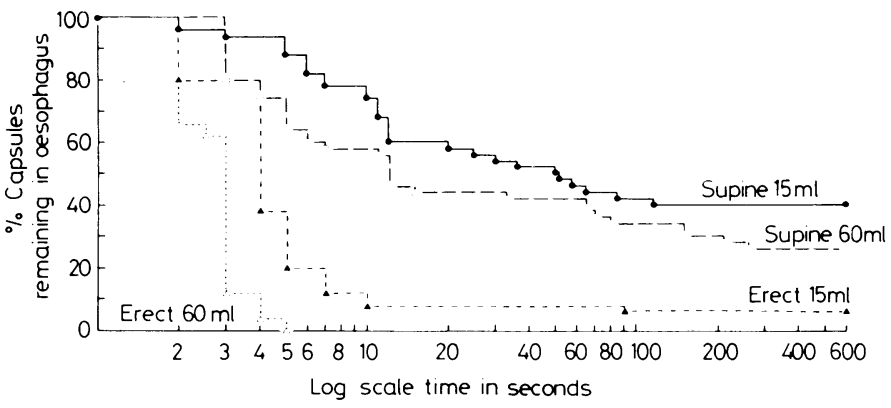

Percentage of capsules remaining in the oesophagus in relation to time unde four different conditions.

\section{Comment}

Barium sulphate tablets have been found ${ }^{3}$ by fluoroscopy to stick in the oesophagus. In our study the effect of posture and drink volume on capsule transit in patients with normal oesophageal motility (as assessed by barium swallow) was highly significant. This has not previously been shown. Evans and Roberts ${ }^{3}$ found a positive correlation between the presence of hiatus hernia reflux and disordered peristalsis and tablet sticking. This was not found in our study although delayed passage was always associated with gastro-oesophageal reflux.

Hard gelatin capsules absorb water and become adherent to the moist mucosa of the oesophagus if their passage is delayed for longr than two minutes. Once adherent disintegration occurs and the contenfts are released on to the non-absorptive stratified squamous muco. Variations in drug absorption are possibly related to oesophageal disintegration rather than to gastric or intestinal drug malabsorptiog. Evans and Roberts ${ }^{5}$ also compared hard and soft gelatin capsules butt found no significant difference between the sticking rates of either. In only $22 \%$ of their patients did capsules stick. Our rate of $52 \frac{\bar{Q}}{\sigma^{\circ}}$ was similar to their tablet sticking rate of $58 \%$.

There was a positive correlation between history of dysphage difficulty in swallowing tablets and sensation of tablets stickimg (mainly in the throat), and delayed capsule transit; yet only three of $26(11.5 \%)$ patients were aware that a trial capsule had lodged in their oesophagus. It is even more important, therefore, for the prescribing doctor to be aware of the potential problem and to advise patients take drugs with a drink while standing. This should avoid any locgl irritant effect of drug contact and ensure more regular absorption. 3

We thank Mr C Lewis (staff pharmacist) for preparing the capsules, N000 G Wilkinson (superintendent radiographer) for her patience, $\mathrm{Mr}$ A Hughes, for statistical advice, $\operatorname{Dr}$ M J Campbell for editorial help, and Jayne Hugh and Nicola Eberle for typing the manuscript.

1 Collins FJ, Matthews HR, Baker SE, Strakova JM. Drug-induced oesophageal injury. Br Med $\mathcal{F} 1979$; i:1673-6.

* Channer KS, Hollanders D. Tetracycline-induced oesophageal ulceration Br Med ₹ $1981 ; 282: 1359-60$.

${ }^{3}$ Evans KT, Roberts GM. Where do all the tablets go ? Lancet 1976, 1237-9.

- Siegel S. Non-parametric statistics for behavioral sciences. New Yo McGraw-Hill, 1956.

${ }^{5}$ Evans KT, Roberts GM. The ability of patients to swallow capsules Clin Hosp Pharm 1981 ; 6:207-8.

(Accepted 13 August 1982)

Bristol Royal Infirmary, Bristol BS2 8HW

K S CHANNER, BSC, MRCP, registrar in neurology and general medicine J VIRJEE, FRCR, consultant radiologist

\section{Different interactions of indomethacin and sulindac with thiazides in hypertension}

Treatment with anti-inflammatory drugs has caused problems when administered with loop diuretics in the treatment of congestive healt failure. ${ }^{1}$ Attenuated hypotensive effect of thiazides has recently beion described during concomitant treatment with indomethacin. ${ }^{2}$ It was concluded that products formed by the arachidonic acid cyclooxygenase contribute to the regulation of blood pressure, as indemethacin inhibits the cyclo-oxygenase. Sulindac inhibits exclusively the extrarenal prostaglandin synthesis both in vitro and in vivo, ${ }^{3}$ while indomethacin inhibits the prostaglandin synthesis in all organs. Fo elucidate the influence of renal prostaglandins on the antihypertensite effects of thiazides we investigated the effect of thiazides during tref ment with indomethacin and sulindac.

\section{Patients, methods, and results}

Ten men (median age 50 years) with essential hypertension (WHO classit cation I) with supine diastolic pressure higher than $100 \mathrm{~mm} \mathrm{Hg}$ before drus treatment were selected for the study. All patients were in good health a had no history of dyspeptic symptoms. Serum concentrations of electrolytos and creatinine were within normal ranges. The protocol was approved by local ethical committee and the patients gave informed consent to the studf.

The patients were treated with thiazide (five with $10 \mathrm{mg}$ bendrofluazide (Centyl) and five $100 \mathrm{mg}$ hydrochlorothiazide and $10 \mathrm{mg}$ amiloride (Moduretic)). After a four-week run-in period all patients received either in methacin capsules, $100 \mathrm{mg}$ daily, or sulindac tablets, $400 \mathrm{mg}$ daily, for fow 